\title{
ENSEÑANZA MOTIVADA DEL DERECHO INTERNACIONAL PRIVADO EN EL SIGLO XXI: ETHOS, PATHOS Y LOGOS
}

\section{MOTIVATED TEACHING OF PRIVATE INTERNATIONAL LAW IN THE 21ST CENTURY: ETHOS, PATHOS AND LOGOS}

\author{
JAVIER CARrascosa GonzÁlez \\ Catedrático de Derecho internacional privado \\ Universidad de Murcia \\ ORCID ID: 0000-0002-0347-7985 \\ Recibido: 09.06.2021 / Aceptado: 25.06.2021 \\ DOI: https://doi.org/10.20318/cdt.2021.6283
}

\begin{abstract}
Resumen: El presente trabajo constituye una reflexión sobre las líneas básicas de la enseñanza del Derecho internacional privado en el contexto líquido de la sociedad del siglo XXI. El docente de Derecho internacional privado debe asumir que esta disciplina se entiende mejor cuando se expone de manera sencilla y directa. Debe también estar preparado para explicar las paradojas jurídicas aparentes del Derecho internacional privado y asumir que es necesario estudiar otras ramas del Derecho antes de comenzar a reflexionar sobre el Derecho internacional privado. En tal sentido, el Derecho internacional privado se enseña mejor a través de sus problemas abiertos o nudos problemáticos de Derecho internacional privado. Del mismo modo, la enseñanza del Derecho internacional privado consigue motivar a los estudiantes si se transmite la visión de un Derecho internacional privado que logra resultados justos, que mueve los corazones de las personas y que constituye un discurso intelectual y estéticamente bello.

Palabras clave: enseñanza del Derecho internacional privado, paradojas jurídicas, problemas de Derecho internacional privado, ethos, pathos, logos.
\end{abstract}

Abstract: This essay is a reflection on the basic lines of the teaching of private international law in the liquid context of 21 st century society. Teachers of private international law must assume that the discipline is best understood when it is presented in a simple and straightforward manner. He or she must also be prepared to explain the apparent legal paradoxes of private international law and to accept that it is necessary to study other branches of law before beginning to reflect on private international law. Private international law is best taught through its open problems. Similarly, the teaching of private international law can motivate students if it conveys the vision of a private international law that achieves fair results, that moves people's hearts and that operates as an intellectually and aesthetically beautiful discourse.

Keywords: teaching of private international law, problems of private international law, ethos, pathos, logos, legal paradoxes.

Sumario: . Líneas básicas de la enseñanza del Derecho internacional privado en el contexto líquido de la sociedad del siglo XXI. 1. Qué enseñar y cómo enseñar Derecho internacional privado. 2. Contenido y narrativa del Derecho internacional privado. II. Claridad en la exposición y transmisión docente del Derecho internacional privado. 1. Las paradojas jurídicas aparentes del Derecho internacional privado. 2. Bases jurídicas previas para el aprendizaje del Derecho internacional privado. 3. Enseñanza progresiva del Derecho internacional privado y la pirámide de MASLOW. III. Enseñanza reflexiva del Derecho internacional privado. 1. Flexibilidad de pensamiento en Derecho internacional privado. 2. Nudos problemáticos de Derecho internacional privado. Algunos ejemplos. A) Leyes de 
policía y partes débiles en la contratación internacional. B) Reglamento Bruselas II-bis y menores con residencia habitual en terceros Estados. C) Falta de prueba voluntaria del Derecho extranjero. 3. Pensamiento divergente y dobles líneas de reflexión de docentes y estudiantes en Derecho internacional privado. IV. Motivación de los estudiantes como herramienta discursiva y Derecho internacional privado. Ethos, pathos, logos. 1. Ethos: el Derecho internacional logra resultados justos. 2. Pathos: el Derecho internacional privado mueve los corazones. 3. Logos: el Derecho internacional constituye un discurso intelectual y estéticamente bello. V. Contexto democrático de la enseñanza del Derecho internacional privado. 1. El Derecho internacional privado es un saber argumentativo. 2. Modo constitucional y modo europeo de pensar el Derecho internacional privado. VI. Reflexiones.

\section{Líneas básicas de la enseñanza del Derecho internacional privado en el contexto líquido de la sociedad del siglo XXI}

\section{Qué enseñar y cómo enseñar Derecho internacional privado}

1. La primera cuestión que un buen docente de Derecho internacional privado debe tener clara es el objeto de su enseñanza ${ }^{1}$. Es ésta una cuestión común a todas las ramas y sectores del Derecho: delimitar el objeto de la disciplina, materia, contenido o campo temático a enseñar es la primera cuestión². En otras palabras, y por lo que a este trabajo concierne, es preciso que el docente sea consciente de qué es y cómo funciona el Derecho internacional privado que se dispone a enseñar. Es ésta una cuestión crucial sobre la que se han vertido ríos de tinta desde hace casi doscientos caños, esto es, desde el momento en el que en las Universidades europeas y norteamericanas arranca un proceso de reflexión sobre la autonomía docente de Derecho internacional privado respecto del derecho internacional público y respecto, también, de otras disciplinas jurídicas integradas en el Derecho Privado ${ }^{3}$. En esencia, cabe afirmar que para enseñar correctamente Derecho internacional privado, el docente debe tener interiorizado, a un nivel muy profundo, qué es el Derecho internacional privado, cuáles son sus fuentes de producción jurídica, cuáles son sus objetivos y cuál es su función. Debe clarificar el objeto de su enseñanza, purgarlo de elementos contaminantes y debe también fijar la posición del Derecho internacional privado en el sistema legal español y europeo. Es el modo de alcanzar estrategia operacional equilibrada en el punto de partida de la docencia del Derecho internacional privado.

2. Es cierto que el concepto de "Derecho internacional privado" ha sido objeto, subraya G. BARILE, de una controversia interminable que no cesa ${ }^{4}$. Como han escrito A.-L. Calvo CaraVaca / J. CARrascosa GonzÁLEZ, en relación con el Derecho internacional privado se ha discutido todo: su objeto, sus presupuestos, su contenido, su función y, por supuesto, su propia denominación como sector del Derecho5. Es

${ }^{1}$ Este trabajo ha sido realizado en el marco del Proyecto de investigación LOGOS (Fundación BBVA) "Los principios del Derecho romano en el Derecho europeo del siglo XXI" (Proyecto Roma-Europa: IP Javier Carrascosa). https://proyectoromaeuropa.com/), del Grupo de Innovación Docente GID 22 "Ciencia jurídica aplicada y docencia creativa” de la Universidad de Murcia (coordinador: Javier Carrascosa), del Grupo de investigación de la Universidad de Murcia E070-05 "Derecho internacional privado europeo" (IP Javier Carrascosa), de la "Red Europa-España de Derecho internacional privado", (coordinador: Javier Carrascosa). http://www.redespañaeuropa.es/), así como del Grupo Accursio: investigación, docencia y práctica del Derecho internacional privado (www.accursio.com), dirigido por Javier Carrascosa.

2 A. Calvo-Bernardino / A.C. Mingorance-Arnáiz, "La estrategia de las universidades frente al Espacio Europeo de Educación Superior", Revista Complutense de Educación, vol. 20, nº 2, 2009, pp. 319-342; M. MARTínez MARTíN / M. VIADER JuNYENT, "Reflexiones sobre aprendizaje y docencia en el actual contexto universitario", Revista de Educación, No Extraordinario 1, 2008, pp. 213-234.

3 Tema que ocupó y preocupó en buena medida a la doctrina italiana de los años cincuenta y sesenta del pasado siglo XX. Vid. P. FoIS, "L'insegnamento del diritto internazionale durante il Novecento", RDIPP, 1992, pp. 17-28; M. MIELE, "Per l'autonomia didattica del diritto internazionale privato", Giornale dell'Universitá, vol.VI, 1956, núm.2, pp. 55-56; R. DE NovA, "Ancora per l'autonomia del diritto internazionale privato", Giornale dell'Universitá, 1957, vol.VII, núm.1, pp. 13-14; R. DE Nova, "Diritto internazionale pubblico e diritto internazionale privato nell'ordinamento degli studi", Diritto Internazionale, 1959, vol.XIII, pp. 206-209.

4 G. Barile, "Diritto internazionale privato", Enciclopedia del diritto, Giuffrè, Milano, vol.XII, 1964, pp. 1035-1063.

5 A.-L. Calvo Caravaca / J. Carrascosa GonzÁlez (directores), Tratado de Derecho internacional privado, vol. I, primera edición, editorial Tirant Lo Blanch, València, 2020, pp. 83-96. 
realmente difícil explicar y exponer y transmitir una disciplina jurídica que duda sobre sí misma, como ya indicaron los clásicos ${ }^{6}$. No e momento ni lugar para reproducir aquí este debate académico. Basta recordar que la "concepción privatista" del Derecho internacional privado es la que cuenta con más consenso académico y legal en todo el mundo. En dicha perspectiva, el Derecho internacional privado debe entenderse como el sector del Derecho que regula las relaciones jurídicas entre particulares en un escenario transfronterizo o multijurisdiccional, escribe J. BASEDOw ${ }^{7}$. Puede, tanto afirmarse que se debe enseñar el Derecho internacional privado en su versión privatista, por su fuerte coherencia científica, por su visión completa de la realidad jurídica de las relaciones legales de los particulares en un contexto internacional, y por el hecho , incontestable de que, hoy día, es la visión que siguen la inmensa mayoría de las legislaciones estatales de Derecho internacional privado en el mundo. En definitiva, y como se ha puesto en otro lugar, la realidad muestra que el Derecho internacional privado constituye un sector del Derecho Privado que responde a una lógica de Derecho Privado: es aquel sector del ordenamiento jurídico que estudia las relaciones jurídicas entre los particulares que se desarrollan en un escenario internacional ${ }^{8}$. Ése es el Derecho internacional privado que hoy debe enseñarse, transmitirse y explicarse.

3. La segunda cuestión a tener en cuenta por un docente de Derecho internacional privado que se preocupe de enseñar correctamente el mejor Derecho internacional privado es la determinación del "cómo enseñar bien Derecho internacional privado". Una programación funcional sistemática es necesaria. Se trata de concretar, en este momento, cuáles son las líneas básicas que deben presidir la labor de enseñanza del Derecho internacional privado. Los ejes fundamentales y básicos que deben orientar la labor educativa en Derecho internacional privado, -y que no deben confundirse con los objetivos docentes-, pueden condensarse en estos cuatro extremos: (i) claridad y sencillez en la exposición, (ii) reflexión y argumentación jurídica del contenido, (iii) utilidad en el resultado y (iv) creación de un contexto democrático y de un modo de pensar constitucional y europeo del Derecho internacional privado.

4. En el presente estudio se aborda, modestamente, sólo dicho perfil, esto es, las líneas básicas que puede resultar aconsejable seguir para enseñar Derecho internacional privado en la actualidad, esto es, lo que en otros tiempos se denominaba el "método de enseñanza" del Derecho internacional privado. Queda para otro momento el análisis de la función docente de la Universidad y la teoría educativa en el Derecho internacional privado, la precisión del contenido de la enseñanza del Derecho internacional privado, las técnicas y los materiales didácticos a utilizar para la enseñanza del Derecho internacional privado, los objetivos a perseguir en la enseñanza del Derecho internacional privado, la planificación de la evaluación de la disciplina y una reflexión sobre la perspectiva institucional de la docencia del Derecho internacional privado. Todo a su tiempo.

\section{Contenido y narrativa del Derecho internacional privado}

5. En este sentido, resulta importante señalar este momento la gran diferencia que se aprecia entre el contenido de Derecho internacional privado a enseñar y la narrativa del Derecho internacional privado.

El "contenido" del Derecho internacional privado dirige su atención hacia lo que se enseña: las normas, la jurisprudencia, las teorías propias de Derecho internacional privado, la doctrina jurídica propia de esta disciplina jurídica. Es el sistema legal, con todos sus componentes. Es la materia bruta o

\footnotetext{
${ }^{6}$ P. ARminjon, "L'objet et la méthode du droit international privé", Recueil des Cours de l'Académie de Droit international de La Haye, vol.21, 1928, pp. 429-512; D.J. EvrigenIs, "Tendances doctrinales actuelles en droit international privé", Recueil des Cours de l'Académie de Droit international de La Haye, vol.118, 1966, pp. 313-432.

7 J. BASEDOw, «The Law of Open Societies - Private Ordering and Public Regulation of International Relations. General Course on Private International Law", Recueil des Cours de l'Académie de Droit international de La Haye, 2012, vol. 360, pp. 9-14.

8 J. Carrascosa González, Derecho internacional privado y dogmática jurídica, Granada, Editorial Comares, Colección "Ciencia Jurídica y Derecho Internacional”, Granada, 2021, pp. 2-32.
} 
la materia prima de la docencia del Derecho internacional privado. Es el mármol que se extrae del yacimiento sin una forma definida. Frente a ello, la "narrativa" es una noción que indica cómo se puede y/o se debe enseñarse dicho contenido.

Así, por ejemplo, el art. 9.1 CC es la materia prima, es el contenido. Es un dato normativo objetivo cualquiera que sea el docente que enseña Derecho internacional privado. Ahora bien, el contenido del art. 9.1 CC puede transmitirse de maneras muy diferentes según quien sea el docente, la perspectiva que adopte y el objetivo que persiga. El docente que sabe penetrar en los orígenes, las razones, los motivos y los efectos del art. 9.1 CC es el docente que enseña un buen Derecho internacional privado. Es el jurista que sabe motivar a sus estudiantes. El docente que muestra los grandes beneficios de ese precepto legal para la vida de millones de personas, la belleza intelectual de su construcción y la historia que atesora en su interior el art. 9.1 CC es el docente que es capaz de hacer arte, porque el arte descansa en la narrativa, no en el contenido, precisa J. SutHerLAND ${ }^{9}$. El art. 9.1 CC no es una pieza de museo, sino una norma de conflicto de leyes que recoge un punto de conexión, la nacionalidad de la persona física que, con frecuencia, comporta grandes beneficios para los sujetos que despliegan una vida transfronteriza, recuerdan J. BASEDOw y A.V.M. STRUYCKEN ${ }^{10}$. La narrativa que acompaña al art. 9.1 CC y a la aplicación de la Ley nacional al llamado "estatuto personal" es más atractiva que el contenido mismo del precepto, como muestra el sugerente curso de F. SALERNo ${ }^{11}$. En muchos casos, el art. $9.1 \mathrm{CC}$ permite que las personas superen las fronteras estatales sin obstáculos jurídicos, lo que se traduce en una vida más fluida y mejor para las mismas, indica A. VetTOReL ${ }^{12}$.

\section{Claridad en la exposición y transmisión docente del Derecho internacional privado}

\section{Las paradojas jurídicas aparentes del Derecho internacional privado}

6. El Derecho internacional privado es un sector del ordenamiento jurídico que presenta argumentos, nociones y expresiones particularmente complejas y de elevado nivel técnico. Y no sólo eso. En efecto, también en esta óptica, el Derecho internacional privado provoca las conocidas como "paradojas jurídicas aparentes", resultados legales que parecen imposibles en Derecho pero que, como es evidente, suceden, acontecen y ocurren, pues son perfectamente posibles. Así lo demuestra la realidad.

No es sencillo explicar a los estudiantes neófitos e incluso a juristas ya formados pero no versados en conocimientos sofisticados de Derecho internacional privado, por ejemplo, que una persona puede estar casada para el Derecho español pero divorciada para el Derecho inglés ${ }^{13}$. Legalmente casada según el Derecho de Marruecos con dos personas pero casada, según el Derecho italiano, con sólo una de ellas, subraya C. CAMPIGLIO ${ }^{14}$.

No resulta fácil tampoco hacer comprender al jurista que una prenda mobiliaria puede dejar de existir y de producir los efectos jurídicos que le son propios si el bien sobre el que la prenda recae se traslada desde el Estado donde se ha constituido la garantía a otro Estado distinto, como expone Z. Crespi ReghizZi ${ }^{15}$.

\footnotetext{
9 J. Sutherland, Cincuenta cosas que hay que saber sobre Literatura, Ariel, Barcelona, 2011, pp. 36-37.

10 J. BASEDOw, "Das Staatsangehörigkeitsprinzip in der Europäischen Union", IPRax, 2011-II, pp. 109-115; = A.V.M. STRUYCKEN, "State nationality and religious family law: some notes", NILR, 65, 3, 2018, pp. 481-496.

11 F. Salerno, "The identity and continuity of personal status in contemporary Private International Law", Recueil des Cours de l'Académie de Droit international de La Haye, vol. 395, 2019, pp. 9-198.

12 A. Vettorel, «La continuitá transnazionale dell'identitá personale: riflessioni a margine della sentenza Henry Kismoun», Rivista di Diritto internazionale privato e processuale, 2014, pp. 341-358.

13 J. Carrascosa GonzÁlez, "Casados en un país, divorciados en otro. La vida es tan relativa....", en http://accursio.com/ blog/?p=1091, 25 abril 2020.

${ }_{14}$ C. Campiglio, "Matrimonio poligamico e ripudio nell'esperienza giuridica dell'occidente europeo", Rivista di Diritto internazionale privato e processuale, 1990, vol.XXVI, pp. 853-908.

15 Z. Crespi Reghizzi, Lex rei sitae e disciplina delle garanzie mobiliari nel diritto internazionale privato, Milano, Giuffrè, 2007, pp. 8-17.
} 
Incluso más allá, en el plano ontológico-jurídico, el Derecho internacional privado hace templar los cimientos del discurso legal al provocar la duda sobre el significado de conceptos básicos en Derecho. Así, un bien físico puede ser considerado „mueble“ en Francia pero „inmueble“ en España. Del mismo modo, en Derecho internacional privado, una persona puede tener unos apellidos para el Derecho turco y otros bien distintos en Derecho español. De ese modo la persona se diluye, se hace líquida, es una persona que, en realidad, son dos personas. La personalidad jurídica de un ser humano se divide y nacen dos personas porque el Derecho internacional privado es así. En ocasiones, puede evitarse ese resultado bipolar, escriben F. JAULT-SESEKE / É. PATAUT, pero otras veces constituye un resultado inevitable ${ }^{16}$.

El Forum Shopping es también un caso de "paradoja aparente" del Derecho internacional privado cuya explicación a los juristas noveles no resulta sencilla. Y es que no es fácil explicar y asumir que un miso supuesto de Derecho internacional privado dispone de un régimen jurídico diferente según cuál sea el Estado cuyos tribunales y/o autoridades conocen del mismo. Sin embargo, debe aceptarse, con M. CheCa Martínez, que es así, precisamente así porque, en realidad, el Forum Shopping es un fenómeno natural, consecuencia ineludible del hecho, innegable, de un mundo físico dividido en Estados que cuenta cada uno de ellos con su propia organización judicial y con su propia legislación material y sus propias normas de Derecho internacional privado ${ }^{17}$. Existen objetivos que todos los Estados comparten, explica M. LEHMANN, y que por ello pueden implementarse a través de normas uniformes internacionales, pero existen otros que conservan un "aura nacional"18. Es ahí donde florece el Forum Shopping. Un fenómeno que, aunque se ha mirado mal, presenta elementos positivos, escribe F. FERRARI ${ }^{19}$. Entre ellos se cuenta su potencial en la lucha contra el etnocentrismo e incluso su relativización del legeforismo, apunta J. SCHACHERREITER ${ }^{20}$.

\section{Bases jurídicas previas para el aprendizaje del Derecho internacional privado}

7. Por otro lado, es el Derecho internacional privado un sector del ordenamiento que exige un conocimiento profundo previo, cuanto menos, del Derecho Civil, mercantil, procesal y laboral. Por eso el Derecho internacional privado es una buena excusa para explorar los pequeños secretos de otras ramas del Derecho, escriben M.-L. Niboyet / G. De Geouffre de La Pradelle ${ }^{21}$. Exige también el manejo de ciertas dosis de Derecho material extranjero, una destreza, indica C. KohLer, en el Derecho comparado $^{22}$. Estudios éstos que no constituyen mera especulación, sino que otorgan al Derecho internacional

${ }^{16}$ F. Jault-Seseke/É. Pataut, "Le citoyen européen et son nom”, en B. Hess / E. Jayme / H.-P. Mansel (HrsG.), Europa als Rechts- und Lebensraum: Liber amicorum für Christian Kohler zum 75. Geburtstag am 18. Juni 2018, Bielefeld, Gieseking, 2018, pp. 371-384.

17 M. Checa Martínez, "Fundamentos y límites del forum shopping: modelos europeo y angloamericano", Rivista di Diritto internazionale privato e processuale, 1998, n.3, pp. 521-556. También muy bien explicado con referencias jurisprudenciales españoles en Y. Romero Matute, "Fraude de Ley y Forum Shopping en los estrados del Tribunal Supremo", en A.-L. Calvo Caravaca / J. Carrascosa GonzÁlez (Dir.), El Tribunal Supremo y el Derecho Internacional Privado, vol. 1, Murcia, Rapid Centro Color S.L., 2019, pp. 137-152.

18 M. Lehmann, "Regulation, global governance and private international law: squaring the triangle", Journal of Private international law, 2020, n.1, vol. 16, pp. 1-30.

19 F. FERRARI, „Forum Shopping despite Unification of Law“, Recueil des Cours de l'Académie de Droit international de La Haye, vol.21, 2021, pp. 1-336. Antes ya en F. Ferrari, „Forum shopping: pour une définition ample dénuée de jugements de valeurs", Revue critique de droit international privé, 2016, pp. 85-105.

20 J. SCHACHERREITER, „Das Verhängnis von Ethnozentrismus und Kulturrelativismus in der Rechtsvergleichung - Ursachen, Ausprägungsformen und Strategien zur Überwindung“, RabelsZ, 2013.II, pp. 272-299. También J. SCHACHERREITER, „Das Verhängnis von Ethnozentrismus und Kulturrelativismus in der Rechtsvergleichung -- Ursachen, Ausprägungsformen und Strategien zur Überwindung“", RabelsZ, 2013-2, pp. 272-299.

${ }^{21}$ M.-L. Niboyet / G. De Geouffre de La Pradelle, Droit international privé, 6a ed., Paris, Lextenso éditions, LGDJ, 2017, p. XXV: «Finalement, le droit international privé n'est pas simplement l'instrument qui permet de surmonter les difficultés suscitées par le "phénomène de la frontière». C'est également un bon moyen de pénétrer les petits secrets des autres branches du droit».

${ }^{22}$ C. KoHLer, "Gelebte Rechtsvergleichung am EuGH: europäisches Kollisionsrecht in Theorie und Praxis", Zeitschrift für europäisches Privatrecht, 27, 2, 2019, pp. 337-357. en similar sentido, L. REED, "Comparative Law in the Supreme Court of the United Kingdom", RabelsZ., 2018-3, pp. 563-575. 
privado, como sostiene N. Marchal Escalona, un marcado nivel de realismo ${ }^{23}$. En efecto, una implementación logística paralela permite descubrir, por ejemplo, que la norma de conflicto de leyes adquiere todo su significado si el estudiante conoce el resultado al que dicha norma puede conducir. También ayuda sobremanera interiorizar unas ideas claras sobre las relaciones entre el Derecho internacional Público y el Derecho europeo con el Derecho internacional privado. Sin dichas bases jurídicas previas no se entiende bien el Derecho internacional privado y tampoco se enseña correctamente.

\section{Enseñanza progresiva del Derecho internacional privado y la pirámide de MASLOW}

8. La complejidad técnica y axiológica del Derecho internacional privado a la que se ha hecho referencia requiere que el docente del Derecho internacional privado se esfuerce al máximo por exponer la argumentación de que se trate del modo más sencillo y claro posible. Por pasos y por grados, de lo más sencillo a lo más complejo, una enseñanza progresiva. En una aplicación intelectual y docente de la pirámide de MASLOW, ello supone, para el Derecho internacional privado, "avanzar por estadios en la escalera del Derecho": de lo básico a lo sofisticado. A tal efecto es preciso subrayar ciertos datos previos que impulsan una enseñanza del Derecho internacional privado guiada por una idea de flexibilidad direccional coordinada.

9. En primer término, el docente debe proceder a una intensa preparación de la enseñanza del Derecho internacional privado. La rigurosidad y síntesis en la exposición de los resultados de la investigación constituye dos extremos que requieren una labor previa de estudio, sistematización y clarificación por parte del docente que es altamente exigente consigo mismo.

10. En segundo lugar, en la exposición y transmisión de los conocimientos de Derecho internacional privado, el docente debe renunciar a buena parte de su bagaje científico personal. Ese "equipaje intelectual refinado", que habrá servido al docente, sin duda, para preparar la exposición y sintetizar los resultados, es conveniente mantenerlo aislado para que no oscurezca los resultados del estudio y su transmisión a los juristas que hacen sus primeras armas en el Derecho internacional privado. Se trata, en todo caso, de una mera renuncia externa en aras de la claridad y sencillez de la enseñanza del Derecho internacional privado. Las aguas corren siempre por debajo de la superficie y son las que hacen que la tierra fructifique.

\section{Enseñanza reflexiva del Derecho internacional privado}

\section{Flexibilidad de pensamiento en Derecho internacional privado}

11. La reflexión subjetiva que debe transmitir el docente del Derecho internacional privado constituye un importante elemento que debe presidir, igualmente, la labor didáctica del mismo. El profesor de Derecho internacional privado debe "pensar lo estudiado", transmitir su fundada opinión de experto en Derecho internacional privado a los estudiantes y no comunicar un vagón que rebosa de interminables datos legales, fechas de sentencias, extraños y a veces impronunciables nombres de casos fallados por tribunales españoles y extranjeros y abstrusas teorías muchas veces oscuras debidas a estudiosos esotéricos del Derecho internacional privado. Con ello se consigue que los estudiantes tomen también partido en relación con ciertos puntos polémicos del Derecho internacional privado,

${ }^{23}$ N. Marchal Escalona, "La importancia del Derecho comparado en la enseñanza del Derecho internacional privado", en M.A. Cebrián Salvat / I. Lorente Martínez (directoras), Innovación docente y Derecho internacional privado, Ed. Comares, Granada, 2019, pp. 35-52. También M.A. CeBrí́N SALVAT, “«Case method» y «case study method»: experiencias de aplicación en un sistema de base legal”, en M.A. Cebrián SAlvat / I. Lorente Martínez (directoras), Innovación docente y Derecho internacional privado, Ed. Comares, Granada, 2019, pp. 159-171. 
que asuman que ciertos aspectos de la disciplina no son pacíficos y que varios puntos de vista, teorías o posiciones, pueden tener argumentos a su favor.

\section{Nudos problemáticos de Derecho internacional privado. Algunos ejemplos.}

12. El Derecho internacional privado se encuentra lleno de "nudos problemáticos". Se trata de aquellos "elementos clave" que permiten desarrollar una enseñanza reflexiva del mismo y que, precisamente por ello, hacen crecer las capacidades argumentativas de los estudiantes. Tres ejemplos, de entre los muchos existentes, bastarán para poner de relieve la utilidad de una enseñanza reflexiva del Derecho internacional privado construida sobre los nudos problemáticos de esta disciplina jurídica, una enseñanza que se edifica sobre los problemas y no los evita, en las palabras de E.J. WooD ${ }^{24}$.

\section{A) Leyes de policía y partes débiles en la contratación internacional}

13. En primer lugar, puede destacarse la discusión interminable en torno a la cuestión de saber si las llamadas "leyes de policía" pueden aplicarse a un contrato internacional a través del art. 9 RR-I con el objetivo de proteger a personas o colectivos que disponen de un poder de negociación limitado o que se encuentran en situación de debilidad contractual. Este dilema constituye un debate abierto en el que varias posturas se han mantenido.

14. Recuerda H. Kenfack que el art. 7 CR había planteado la severa duda de saber si en el concepto de "Leyes de policía" debía cubrir tanto las "normas de dirección", como las "normas de protección"25. Las "normas de dirección" son aquéllas que protegen intereses generales o públicos, explica J. BASEDOW ${ }^{26}$. Son normas dictadas "con criterios de Derecho Público", normas que persiguen un objetivo económico-político, como desveló I. GUARDÁNs ${ }^{27}$. Por el contrario, las llamadas "normas de protección" son las que protegen la situación jurídica de ciertas personas o colectivos que se encuentran en una "posición contractual débil", como los trabajadores, consumidores, asegurados, agentes comerciales, etc., y que tratan de "reestablecer el equilibrio" entre los contratantes. El debate generado en torno a la cuestión y que giraba sobre la base normativa del art. $7 \mathrm{CR}$ no tuvo un vencedor claro. Ambas posturas parecían perfectamente sostenibles.

15. Más allá del Convenio de Roma de 19 junio 1980, y superado este texto legal, el concepto legal ahora proporcionado por el art. 9.1 RR-I deja claro, de modo radical y definitivo, que a efectos del Reglamento Roma I, las "Leyes de policía" son, exclusivamente, las conocidas como "normas de dirección", como ya había defendido un sector autorizado de la doctrina y significativamente, la jurisprudencia alemana (sent. BGH 19 marzo 1997) ${ }^{28}$. El Cons. (37) RR-I así lo confirma al indicar que las leyes de policía se basan en "consideraciones de interés público". Sin embargo, lo que parece transparente puede no serlo tanto, porque la clarificación aportada por el citado Considerando puede, a su vez, matizarse. El debate continúa, el nudo problemático mantiene su carácter aporético.

${ }^{24}$ EJ.Wood, Problem-Based Learning: Exploiting Knowledge of How People Learn to Promote Effective Learning, Leeds, Gran Bretaña, School of Biochemestry \& Molecular Biology, 2004, disponible en: https://www.tandfonline.com/ doi/full/10.3108/beej.2004.03000006?scroll=top\&needAccess=true.

${ }_{25}$ H. KenfaCK, «Le Règlement (CE) n ${ }^{\circ} 593 / 2008$ du 17 juin 2008 sur la loi applicable aux obligations contractuelles («Rome I»), navire stable aux instruments efficaces de navigation?», JDI Clunet, 2009, pp. 2-39.

26 J. BASEDOw, "European Private Internacional Law of Obligations and Internal Market Legislation -A Matter of Coordination”, en AA.VV., Liber Memorialis Petar Sarcevic. Universalism, Tradition and the Individual, Munich, Sellier, 2006, pp. 13-24.

27 I. Guardáns I Cambó, Contrato internacional y Derecho imperativo extranjero, Pamplona, Aranzadi, 1992, pp. $299-301$.

${ }_{28}$ M. Audit, «Aspects internationaux de la responsabilité des agences de notation», Revue critique de droit international privé, 2011, pp. 581-602; F.J. Garcimartín Alférez, «El Reglamento 'Roma I' sobre ley aplicable a las obligaciones contractuales: ¿Cuánto ha cambiado el Convenio de Roma de 1980?», Diario La Ley, núm. 6957, Sección Doctrina, 30 Mayo 2008 , versión on line. 
16. Todas las normas jurídicas persiguen un objetivo social porque todas ellas apuntan a una determinada ordenación de la sociedad. En tal sentido, todas las normas de Derecho Privado muestran un sesgo social. Todas ellas tratan de introducir un orden en la sociedad. Así, el art. $1171 \mathrm{CC}$ concreta, en Derecho español, cuál es el lugar donde debe realizarse el pago. El objetivo social de dicha disposición es mantener la paz entre los particulares, esto es, que las partes no entren en controversia sobre cuál es el lugar del pago. Ahora bien, al mismo tiempo, las normas de Derecho Privado persiguen satisfacer intereses particulares, el interés de las partes. Así, el art. $1171 \mathrm{CC}$ entiende que, para las partes, lo más adecuado es que el pago se efectúe allí donde se pactó, y en su defecto, allí donde está la cosa y en otro caso, en el lugar del domicilio del deudor, que es el sujeto que debe realizar el pago. Estas soluciones persiguen beneficiar a ambas partes para que el pago se realice al menor coste posible para ambas. El art. $1171 \mathrm{CC}$ presenta una "carga social débil" y una "carga privada fuerte". En realidad, al Estado, -al Estado español, en este caso-, le resulta indiferente que el lugar del pago sea el domicilio del deudor o el domicilio del acreedor. Por ello, puede afirmarse que el art. $1171 \mathrm{CC}$ no constituye una "disposición cuya observancia un país considera esencial para la salvaguardia de sus intereses públicos, tales como su organización política, social o económica". La mayor parte de las normas de Derecho Privado disponen de una carga social reducida y por ello, no pueden considerarse "leyes de policía" en el sentido del art. 9 RR-I. Debe indicarse, demás, que las normas jurídicas de Derecho dispositivo no pueden, en ningún caso, considerarse leyes de policía. En efecto, si son normas que los contratantes pueden derogar en sus relaciones contractuales y sustituirlas por sus propias reglas diseñadas "a medida", ello significa que tales normas no son esenciales para la salvaguardia de los intereses públicos del Estado que las ha dictado.

17. Las normas que protegen a consumidores, trabajadores, agentes, asegurados y otros colectivos y/o personas situadas en "posición contractual débil" son normas de Derecho Privado cuya misión es, precisamente, reestablecer el equilibrio entre las partes en el contrato. Estas normas no buscan, en principio, defender los intereses estatales o públicos. Por tanto, la protección jurídica de estos colectivos (= partes débiles de la relación jurídica) no se puede llevar a cabo, como había sostenido la jurisprudencia francesa, a través del hoy art. 9 RR-I (sent. Cour Cass. Francia 23 mayo 2006) ${ }^{29}$. Tales sujetos se protegen, exclusivamente, en su caso, a través de ciertas normas de conflicto específicas, que para eso están contenidas en el mismo Reglamento Roma I. Así, la protección del consumidor se alcanza a través de los mecanismos previstos en el art. 6 RR-I, y la protección contractual de los trabajadores se lleva a término a través de lo estipulado en el art. 8 RR-I. Ésta es, sostiene correctamente J. BASEDOw, la regla general en el Reglamento Roma ${ }^{30}$.

18. En casos de contratantes situados en el mismo nivel de poder negociador (= no hay "contratante débil"), la protección de la posición jurídica de los contratantes se lleva a cabo a través de la Lex Contractus (Sent. Trib. Rovereto Italia 15 marzo 2007 [liquitated damages y Derecho inglés]) ${ }^{31}$. Es el caso típico de los contratos entre profesionales del comercio internacional, aunque se trata de una empresa minorista y de una empresa multinacional.

19. En el supuesto de contratantes situados en posiciones contractuales más débiles pero que no disponen de una protección en el Reglamento Roma I a través de una norma de conflicto específica, surgen ciertos contrastes valorativos. Es, notoriamente, el caso de los agentes comerciales. Pues bien, en estos supuestos, no es posible extender la aplicación de la normativa de un Estado miembro cuya función exclusiva es proteger a tales personas y colectivos, "contratantes débiles" como son los agentes comerciales, frente al poder negociador y de mercado de los otros "contratantes fuertes", como son los comitentes o principales. Es también, recuerda M.A. CEBRIÁn SALVAT, el caso de los pequeños comercios minoristas que contratan con el gran fabricante, el caso del gran distribuidor que contrata con el pequeño

\footnotetext{
${ }^{29}$ Sent. Cour Cass. Francia 23 mayo 2006, Journal de droit international Clunet, 2007, pp. 537-543.

30 J. BASEDow, «The Law of Open Societies - Private Ordering and Public Regulation of International Relations. General Course on Private International Law", RCADI, 2012, vol. 360, pp. 9-516, esp. pp. 299-301.

${ }^{31}$ Sent. Trib. Rovereto (Italia) 15 marzo 2007, Rivista di Diritto internazionale privato e processuale, 2007, p. 179.
} 
productor o el caso de la gran empresa franquiciadora que contrata con un pequeño comercio franquiciado $^{32}$. La protección de estos sujetos se lleva a cabo a nivel de segundo escalón, esto es, a través de la Ley sustantiva que rige el contrato en virtud del Reglamento Roma I.

20. Ahora bien, es posible que, como mantiene A. Bonomi, para un Estado concreto, sus normas que protegen a consumidores, trabajadores, agentes, etc. presenten un valor crucial en la ordenación de la sociedad ${ }^{33}$. Por ejemplo, en un Estado con un mercado laboral poco estructurado en el que los empresarios tienden a utilizar masivamente contratos temporales y a despedir y contratar contínuamente a los mismos trabajadores, las normas sobre despido adquieren una importancia social estructural de primer orden. Del mismo modo, en un Estado con un mercado inmobiliario que funciona, en su mayoría, al margen de la ley, las normas de defensa de la posición jurídica del inquilino también pueden resultar fundamentales para la ordenación social. Por tanto, cuando los tribunales estiman que las normas de protección de ciertos contratantes específicos son normas cruciales para la defensa de los intereses públicos, de la organización política, social o económica de un Estado, las califican como leyes de policía y las aplican al contrato incluso en el caso de contratantes débiles ya protegidos a través de los arts. $6 \mathrm{y}$ 8 RR-I. Se trata de normas con "propósitos amalgamados", escribe J. BASEDOW ${ }^{34}$. Normas que, al mismo tiempo, sirven al bien colectivo y par a la protección de personas en situaciones de vulnerabilidad. Así, la STSJ Madrid CA de 30 octubre 2013 [transporte aéreo y consumidores] señala que la Constitución española impone a los poderes públicos la obligación de garantizar la defensa de los consumidores, y que tal previsión constituye "un principio rector de la política y social de nuestro Estado", por lo que entiende "que la normativa española de defensa de consumidores y usuarios debe configurarse como norma de policía" 35 . El TJUE ha indicado que incumbe al juez nacional, a la hora de apreciar el carácter de 'ley de policía' de una norma, tener en cuenta "no sólo los términos exactos de aquella ley sino también su concepción general y el conjunto de circunstancias en las que se promulgó, para poder deducir de ello que tal ley reviste carácter imperativo, en la medida en que conste que el legislador nacional la adoptó con la finalidad de proteger un interés considerado esencial por el Estado miembro de que se trate". Es decir, una norma jurídica puede proteger a personas concretas (= consumidores, trabajadores, agentes comerciales) pero deberá ser considerada como una "ley de policía" si esa misma norma protege y defiende, también, objetivos supraindividuales, intereses generales y públicos (STJCE Sala Quinta 9 noviembre 2000, Ingmar GB Ltd contra Eaton Leonard Technologies Inc., STJUE 17 octubre 2013, C-184/12, Unamar, FD 50) ${ }^{36}$. En todo caso, el art. 9 RR-I es una excepción al sistema general de determinación de la Ley del contrato y está sujeto, siempre, a una interpretación restrictiva.

21. Cuestión muy distinta es la relativa a la aplicación unilateral de la normativa sustantiva de un Estado miembro de la UE que desarrolla la Directiva 86/653/CEE del Consejo de 18 diciembre 1986 [coordinación de los derechos de los Estados Miembros en lo referente a los agentes comerciales independientes $]^{37}$. El objetivo fundamental de dicha normativa europea no es elevar la protección jurídica del agente frente al poderdante, sino dotar a todos los Estados miembros de una regulación armonizada del contrato de agencia. Así se extrae del Considerando segundo de la Directiva que se refiere al objetivo de eliminar las "diferencias entre las legislaciones nacionales sobre representación comercial"

32 M.A. Cebrián Salvat, El contrato de franquicia en Derecho internacional privado europeo, Madrid, Marcial Pons, 2018, esp. pp. 99-101.

33 A. BonOMI, "Globalización y Derecho internacional privado", Globalización y comercio internacional, XX Jornadas AEPDIRI, Madrid, 2005, pp. 223-237.

34 J. BASEDOw, „The Effects of Globalization on Private International Law“, en J. BASEDOw / T. Kono, Legal Aspects of Globalization, Kluwer Law International, The Hague - London- Boston, 2000, pp. 11-26.

35 STSJ Madrid CA de 30 octubre 2013 [ECLI:ES:TSJM:2013:16236].

36 STJCE Sala Quinta 9 noviembre 2000, Ingmar GB Ltd contra Eaton Leonard Technologies Inc., Recopilación, 2000, p. I-09305. Texto en $=$ http://curia.europa.eu/juris/document/document.jsf?text=\&docid=45788\&pageIndex $=0 \&$ doclang=en\& mode $=1$ st $\&$ dir $=\& o c c=$ first\&part $=1 \&$ cid=246254. STJUE 17 octubre 2013, C-184/12, Unamar NV vs. Navigation Maritime Bulgare. [ECLI:EU:C:2013:663].

${ }_{37}$ Directiva 86/653/CEE del Consejo de 18 de diciembre de 1986 relativa a la coordinación de los derechos de los Estados Miembros en lo referente a los agentes comerciales independientes (DOCE L 382, de 31 diciembre 1986). 
a fin de que no perjudiquen "el establecimiento y el funcionamiento de los contratos de representación comercial entre un comerciante y un agente comercial establecidos en diferentes Estados miembros". De ese modo, los poderdantes radicados en un Estado miembro A no preferirán comerciar en un Estado miembro $\mathrm{B}$ y no en otro $\mathrm{C}$ por la razón de que el régimen jurídico del contrato de agencia les resulta más favorable en el Estado miembro B que en el Estado miembro C. Pues bien, dicha normativa nacional de un Estado miembro, en la medida en la que proteja un interés esencial de dicho Estado miembro, puede aplicarse a un contrato internacional de agencia a título de "ley de policía". Esto es, para defender intereses estatales, públicos, generales (= homogeneidad legal del mercado), no para defender la posición jurídica del agente frente al poderdante.

Esta perspectiva la confirma la STJUE 9 noviembre 2000, C-381/98, Ingmar, así como la STJUE 17 octubre 2013, C-184/12, Unamar, FD 36 y 37: "el objetivo de la Directiva 86/653 es armonizar el Derecho de los Estados miembros en materia de relaciones jurídicas entre las partes en un contrato de agencia comercial", y no "proteger al agente frente al principal" del mismo modo que se protege a un consumidor frente a un empresario. Por tanto, un tribunal de un Estado miembro A puede aplicar la normativa nacional que regula el contrato de agencia en dicho Estado miembro A en desarrollo de la Directiva 86/653/CEE, pero no para proteger al agente comercial frente al poderdante, sino porque considera que las normas que regulan la situación de los agentes comerciales independientes, en el caso concreto, defienden un interés crucial y general que consiste en otorgar al agente comercial una protección jurídica más amplia que la protección prevista en la Directiva (STJUE 17 octubre 2013, C-184/12, Unamar, FD 52) ${ }^{38}$.

22. En este sentido, el experto, estudioso y docente de Derecho internacional privado, no debe escatimar el carácter problemático de la calificación de una normativa estatal como "Ley de policía" en el caso de que proteja a sujetos concretos. Es un problema no resuelto que admite matices de gran importancia. Para enseñar correctamente Derecho internacional privado es preciso que el docente reflexione sobre los nudos problemáticos del mismo antes de enseñar. Es preciso que tal docente proceda "pensar lo estudiado", "reflexionar el debate jurídico de Derecho internacional privado", antes de transmitirlo a los estudiantes, de modo que no sólo transmite conocimientos legales sino que transmite una cuidada reflexión jurídica. Al hacerlo de este modo, el docente de Derecho internacional privado no comunica confusión ni tampoco una "batalla de teorías", sino que traslada a los estudiantes el arte de la argumentación en Derecho internacional privado.

\section{B) Reglamento Bruselas II-bis y menores con residencia habitual en terceros Estados}

23. Un segundo ejemplo denudo problemático útil para enseñar el mejor Derecho internacional privado puede encontrarse en la precisión del ámbito de aplicación del Reglamento Bruselas II-bis en relación con los menores que poseen su residencia habitual en terceros Estados y progenitores que se divorcian ante tribunales de un Estado miembro. Cuando el sujeto menor de edad según su Ley nacional

${ }^{38}$ STJUE 17 octubre 2013, C-184/12, Unamar NV vs. Navigation Maritime Bulgare [ECLI:EU:C:2013:663], FD 52: “... los artículos 3 y 7, apartado 2, del Convenio de Roma deben interpretarse en el sentido de que la ley de un Estado miembro de la Unión que garantiza la protección mínima prescrita en la Directiva 86/653, ley elegida por las partes en un contrato de agencia comercial, podrá dejar de ser aplicada por el tribunal que conoce del asunto, radicado en otro Estado miembro, para aplicar en su lugar la lex fori, basándose a tal efecto en el carácter imperativo que, en el ordenamiento jurídico de este último Estado miembro, tienen las normas que regulan la situación de los agentes comerciales independientes, pero ello únicamente si dicho tribunal comprueba de manera circunstanciada que, en el marco de la transposición, el legislador del Estado del foro consideró crucial, en el seno del correspondiente ordenamiento jurídico, conceder al agente comercial una protección más amplia que la protección prevista en la citada Directiva, teniendo en cuenta a este respecto la naturaleza y el objeto de tales disposiciones imperativas". Y también FD 36 y 37: "El Tribunal de Justicia ya ha tenido ocasión de declarar que el objetivo de la Directiva 86/653 es armonizar el Derecho de los Estados miembros en materia de relaciones jurídicas entre las partes en un contrato de agencia comercial (....) En efecto, del segundo considerando de dicha Directiva resulta que las medidas de armonización establecidas en ésta tienen como finalidad, entre otras, suprimir las restricciones al ejercicio de la profesión de agente comercial, uniformar las condiciones de competencia dentro de la Comunidad e incrementar la seguridad de las operaciones comerciales". 
(art. 9.1 CC) tenga su residencia habitual en el territorio de un Estado miembro, la competencia judicial internacional de los tribunales españoles en materia de responsabilidad parental se determinará, exclusivamente, con arreglo a los foros recogidos en el Reglamento Bruselas II-bis. Hasta aquí la regla aparece meridianamente clara y así se puede seguir en transparente jurisprudencia (muy correctamente: SAP Zaragoza 20 abril 2012 [menores marroquíes]; con error: AAP Murcia 25 junio 2019 [sentencia de divorcio dictada en Marruecos]). En dicho supuesto, el Convenio de La Haya de 19 octubre 1996 [protección de niños] resulta totalmente inaplicable a la cuestión (art. 61.a RB II-bis) (AAP Barcelona 17 julio 2019 [menor con residencia en Barcelona]; AAP Barcelona 16 abril 2018 [menores con residencia en Ecuador]; AAP Barcelona 17 mayo 2016 [menor con residencia en República Dominicana]). El art. 22 LOPJ resulta también totalmente inaplicable a este supuesto (muy bien: AAP Baleares 25 marzo 2019 [menor residente en Alemania]; con error y confusión: SAP Girona 18 febrero 2011 [custodia de menores]) ${ }^{39}$.

24. Si el menor no tiene su residencia habitual en un Estado miembro de la UE pero sí la tiene en un Estado parte en el Convenio de La Haya de 1996, entonces la competencia internacional de los tribunales españoles para conocer de asuntos relativos a la responsabilidad parental de los menores se decide con arreglo al Convenio de La Haya de 19 octubre 1996 [protección de niños] ${ }^{40}$. Así lo señala la jurisprudencia (SAP Barcelona 28 noviembre 2018 [menores trasladados a Méjico]; AAP Barcelona 16 abril 2018 [menores con residencia en Ecuador]; AAP Barcelona 17 mayo 2016 [menor con residencia en República Dominicana]; SAP Barcelona 10 abril 2015 [menor con residencia habitual en Ecuador]; SAP Madrid 18 junio 2013 [menor con residencia habitual en Méjico] $)^{41}$.

25. Los problemas aparecen como las amapolas en primavera cuando el menor tiene su residencia habitual en un Estado que no es miembro de la UE ni parte en el Convenio de La Haya de 1996. Así lo ha destacado la doctrina, como ponen de reliee los trabajos de M.C. BARUfFI y S. FulL-Lemaire ${ }^{42}$. En este caso, el legislador no es preciso y la confusión total, la incerteza jurídica y el caos absoluto reinan por todas partes. Comienza la aporía y se confirma que el legislador no es perfecto y a veces, con frecuencia, ni siquiera es buen jurista. aplicarse.

En primer término, con arreglo al art. 61.a RB II-bis, el Reglamento Bruselas II-bis no puede

En segundo lugar, con arreglo al Convenio de La Haya de 19 octubre 1996, texto que no se aplica sólo a los menores cuya residencia habitual se encuentra en un Estado parte en dicho convenio, debe aplicarse el citado Convenio de La Haya.

Sin embargo, y no obstante lo anterior, el art. 12.4 RB II-bis, en palmaria contradicción con el art. 61.a RB II-bis, precisa que el foro contenido en dicho precepto legal puede aplicarse a un menor que tiene su residencia habitual en el territorio de un tercer Estado que no sea Estado parte en el Convenio de la Haya de 19 octubre 1996 (SAP León 6 septiembre 2017 [menor con residencia habitual en Senegal]) ${ }^{43}$. Por tanto, en estos casos es preciso afirmar que el art. 12.4 RB II-bis es aplicable al menor con residencia

${ }^{39}$ SAPZaragoza20abril2012[CENDOJ50297370022012100172];AAPMurcia25junio2019[ECLI:ES:APMU:2019:392A]; AAP Barcelona 17 julio 2019 [ECLI:ES:APB:2019:5742A]; AAP Barcelona 16 abril 2018 [ECLI:ES:APB:2018:1367A]; SAP Barcelona 17 mayo 2016 [CENDOJ 08019370182016100381]; AAP Baleares 25 marzo 2019 [ECLI:ES:APIB:2019:127A]; SAP Girona 18 febrero 2011 [CENDOJ 17079370022011100021].

40 Convenio relativo a la competencia, la ley aplicable, el reconocimiento, la ejecución y la cooperación en materia de responsabilidad parental y de medidas de protección de los niños, hecho en La Haya el 19 octubre 1996 (BOE núm. 291 de 2 diciembre 2010).

41 SAP Barcelona 28 noviembre 2018 [ECLI:ES:APB:2018:12248]; AAP Barcelona 16 abril 2018 [ECLI:ES:APB:2018: 1367A]; SAP Barcelona 17 mayo 2016 [CENDOJ 08019370182016100381]; SAP Barcelona 10 abril 2015 [CENDOJ 08019370122015100240]; SAP Madrid 18 junio 2013 [CENDOJ 28079370242013100326].

${ }^{42}$ M.C. BARUfFI, "La riforma del Regolamento Bruxelles II bis e la tutela dell'interesse superiore del minore", en Dialoghi con Ugo Villani, T. II, Bari, Cacucci, 2017, pp. 1087-1092; M.C. BARUfFI, „A child-friendly area of freedom, security and justice: work in progress in international child abduction cases“, Journal of Private international Law, 2018, pp. 385-420; S. Full-Lemaire, „La prorogation de compétence en matière de responsabilité parentale dans le cadre du règlement Bruxelles II bis“, Revue critique de droit international privé, 2019-II, pp. 457-469.

${ }^{43}$ SAP León 6 septiembre 2017 [ECLI:ES:APLE:2017:857]. 
habitual en un tercer Estado que no es Estado miembro ni Estado parte en el Convenio de la Haya de 19 octubre 1996, pues se trata de lex specialis respecto del art. 61 RB II-bis. Ahora bien, si el art. 12.4 RB IIbis no otorga competencia internacional a los tribunales de un Estado miembro, lo cual es perfectamente posible, especialmente en el caso de que los titulares de la responsabilidad parental no lleguen a alcanzar un "acuerdo de elección de tribunal", resultará aplicable el Convenio de La Haya citado y si éste tampoco otorga competencia a los tribunales españoles, se recurrirá al art. 22 LOPJ (AAP Barcelona 16 octubre 2019 [menores con residencia en Bolivia]; SAP Barcelona 5 noviembre 2019 [divorcio y menores con residencia en India] $)^{44}$.

\section{C) Falta de prueba voluntaria del Derecho extranjero}

26. En tercer lugar, un ejemplo clásico de nudo problemático de Derecho de internacional es el relativo a la determinación del Derecho aplicable y de la postura procesal correcta cuando las partes, han podido acreditar el contenido del Derecho extranjero aplicable a tenor de las normas de conflicto europeas o españolas de las que se trata, pero no lo han hecho y adoptan una postura pasiva sobre el particular. El supuesto no requiere explicaciones muy detalladas, pues se trata de un nudo problemático clásico en Derecho internacional privado español que dura mas de cien años ya. Es sabido que cuando la norma de conflicto indica que un supuesto debe regirse por un Derecho extranjero, es éste y no otro, el Derecho estatal el que debe aplicarse al caso. Ahora bien, la LEC 1/2000 guarda silencio en el caso en el que las partes argumentan sus posiciones sobre el Derecho español y no alegan y/o no prueban, de modo satisfactorio, o en modo alguno, el Derecho extranjero, habiendo podido hacerlo. Ante este silencio legal de la LEC 1/2000 se han forjado diversas tesis en doctrina y jurisprudencia. Dos de ellas presentan un claro encaje constitucional y cuentan con apoyos más o menos solventes en la jurisprudencia y en la doctrina ${ }^{45}$. Así, tanto la tesis de la aplicación sustitutiva del Derecho material español como la tesis de la desestimación de la demanda son defendibles. El debate no está en absoluto cerrado tras la entrada en escena del art. 33.3 LCJIMC que se ocupa, como ha observado A.-L. CALvo CARAvaCA, en realidad de otro supuesto distinto, el caso en el que las partes no pueden, materialmente, probar un Derecho extranjero, por circunstancias que se hallan más allá de su esfera de control y posibilidades ${ }^{46}$.

27. La tesis de la aplicación sustitutiva del Derecho material español viene apoyada por ciertos autores que defienden que el sistema español de Derecho internacional privado debe operar como un Fakultatives Kollisionsrecht, como M. Virgós Soriano y F.J. Garcimartín Alférez ${ }^{47}$. Estos autores sostienen que la Ley aplicable a una situación privada internacional es la Ley sustantiva española, a menos que las partes prueben el Derecho extranjero al que remiten las normas de conflicto europeas o españolas. Estos autores afirman que el Derecho extranjero sólo se aplica si las partes lo hacen valer y lo prueban, pero tales partes son libres de prescindir de las normas de conflicto españolas y de indicar al tribunal que desean que el litigio se rija por el Derecho sustantivo español. Aunque el TS se ha ma-

\footnotetext{
${ }^{44}$ AAPBarcelona16octubre2019[ECLI:ES:APB:2019:7771A];SAPBarcelona5noviembre2019[ECLI:ES:APB:2019:13078].

45 A.-L. Calvo Caravaca, "Aplicación judicial del Derecho extranjero en España. Consideraciones críticas", REDI, 2016, pp. 133-156; A.-L. Calvo Caravaca / J. Carrascosa GonzÁlez, "El Derecho extranjero y el TS: la Sala de lo Social contraataca", AEDIP, 2002, pp. 103-114; A.-L. CALVo CARAVACA, "Alegación del Derecho extranjero ante los tribunales españoles. Criterios del Tribunal Supremo", en A.-L. Calvo Caravaca/J. Carrascosa GonzÁlez (Dir.), El Tribunal Supremo y el Derecho Internacional Privado, vol. 2, Murcia, Rapid Centro Color S.L., 2019, pp. 663-686; A.-L. Calvo Caravaca/J. CARRascosa GonZÁlez, "Carga de la prueba del Derecho extranjero ante los tribunales españoles. Criterios del Tribunal Supremo", en A.-L. Calvo Caravaca/J. Carrascosa González (Dir.), El Tribunal Supremo y el Derecho Internacional Privado, vol. 2, Murcia, Rapid Centro Color S.L., 2019, pp. 713-743; A.-L. Calvo CaravaCa, “Aplicación judicial del Derecho extranjero en España. Consideraciones críticas”, REDI, 2016, pp. 133-156.

46 A.-L. Calvo Caravaca, “Aplicación judicial del Derecho extranjero en España. Consideraciones críticas", REDI, 2016, pp. 133-156.

${ }^{47}$ F.J. Garcimartín Alférez, Derecho internacional privado, Cizur Menor, Civitas Thomson Reuters, Madrid, $5^{\mathrm{a}}$ ed., 2019 , p. 238; M. Virgós Soriano / F.J. Garcimartín AlfÉrez, Derecho procesal civil internacional. Litigación internacional, $2^{\mathrm{a}}$ ed., Civitas, Madrid, 2007, pp. 303-309.
} 
nifestado desde hace más de cien años a favor de esta solución, el TC nunca ha afirmado que la tesis de la aplicación sustitutiva del Derecho español ante la falta de prueba del Derecho extranjero sea la única tesis que encaja con la tutela judicial efectiva constitucional (art. $24 \mathrm{CE}$ ). En efecto, ante la falta de prueba del Derecho extranjero, el tribunal debe pronunciarse sobre el fondo del asunto. Esta exigencia deriva de la tutela judicial efectiva (art. $24 \mathrm{CE}$ ). Las partes tienen derecho a una resolución judicial que resuelva el fondo del litigio. El tribunal dispone de dos opciones que se ajustan perfectamente a la tutela judicial efectiva.

28. Según el Tribunal Constitucional, en efecto, es posible seguir una de estas dos opciones, ambas constitucionalmente ajustadas, pues ambas suponen un pronunciamiento sobre el fondo del asunto.

La primera opción consiste en aplicar el Derecho material español, tal y como indica la Sala Primera del TS, y solventar el pleito mediante la aplicación de las normas sustantivas españolas.

La segunda opción radica en desestimar la pretensión de la parte que debió probar el Derecho extranjero. En efecto: la desestimación de la demanda es una respuesta plenamente fundada y motivada, pues toda demanda cuyo fundamento jurídico sea irreal, inexistente o incorrecto, debe ser desestimada (ATC 422/2004 de 4 noviembre 2004 y Voto Particular a la STS, Social, 4 noviembre 2004, SAP Castellón 15 julio 2009 [divorcio entre cónyuges marroquíes]) ${ }^{48}$. Eso sí, en el caso de que resulte aplicable un Derecho extranjero y éste no se prueba por la parte, si el tribunal desestima la demanda, debe fundamentar o justificar dicha decisión desestimatoria de las pretensiones (STC 155/2001 de 2 julio 2001) ) $^{49}$. Sin embargo, es ésta una respuesta constitucional a la falta de prueba del Derecho extranjero por las partes.

El art. $24 \mathrm{CE}$ exige que el tribunal dicte una sentencia sobre el fondo del asunto pese a que no se haya probado el Derecho extranjero aplicable al fondo del asunto. Ello implica que el tribunal no puede recurrir a ninguna de las siguientes opciones: (a) El tribunal no puede, ante la falta de prueba del Derecho extranjero por las partes, proceder a una mera "inadmisión de la demanda"; (b) El tribunal tampoco puede dejar de pronunciarse sobre el fondo cuando la parte demandante debe fundar dicha demanda en un Derecho extranjero y no lo hace (STC 33/2002 de 11 febrero 2002) ${ }^{50}$. En este caso, la demanda debe admitirse y si el Derecho extranjero no se prueba, el tribunal debe resolver el fondo del asunto, bien mediante la aplicación sustitutiva del Derecho material español o bien mediante la desestimación de las pretensiones de las partes. El tribunal no puede dejar de pronunciarse sobre el fondo mediante el subterfugio de declarar que "no está claro" (non liquet) el Derecho que debe aplicar al litigio (art. 1.7 CC).

\section{Pensamiento divergente y dobles líneas de reflexión de docentes y estudiantes en Derecho inter- nacional privado}

29. Muy importante resulta que el docente destaque, en este punto del discurso, que, en torno a estos nudos problemáticos del Derecho internacional privado no sólo no existe una verdad absoluta sino que cualificados expertos en Derecho internacional privado se manifiestan en sentidos distintos e incluso opuestos. Existen líneas de jurisprudencia diferentes, distintas tendencias en la doctrina y ejemplos numerosos de legislaciones que adoptan soluciones diametralmente enfrentadas. El profesor puede y debe transmitir el carácter abierto de estas cuestiones y dar "opciones de pensamiento divergente" a los estudiantes, todas ellas debidamente argumentadas y bien fundadas en Derecho. De este modo, la "primera reflexión subjetiva del docente" de Derecho internacional privado da lugar a una "segunda reflexión subjetiva" de los estudiantes. Se supera, así, un pretendido, pero, como es claro, inexistente carácter neutro de los conocimientos de Derecho internacional privado transmitidos. Ello no debe conducir a la perplejidad sino a aceptar el desafío de "argumentar mejor" en Derecho. Como ha explicado P. KINSCH, es hora de abandonar "une vision très classique (et idéalisée) du droit international privé", en la cual "les règles de

\footnotetext{
48 ATC 422/2004 de 4 noviembre 2004 [RTC 2004\422 AUTO]; STS, Social, 4 noviembre 2004 [CENDOJ 28079140012004101202]; SAP Castellón 15 julio 2009 [CENDOJ 12040370012009100141].

49 STC 155/2001 de 2 julio 2001 [RTC 2001\155].

${ }^{50}$ STC 33/2002 de 11 febrero 2002 [R. 2002\3107].
} 
celui-ci sont nettement séparées de considérations politiques". En efecto, es claro que "cette conception n'a cependant jamais correspondu parfaitement à la réalité", puesto que el Derecho internacional privado está lleno de "considérations politiques, par opposition aux considérations techniques", que buscna la "défense d'intérêts publics (ou d'intérêts politiques) proprement dits, mais aussi définition de politiques, législatives et jurisprudentielles, qui influent directement sur les solutions adoptées" ${ }^{\text {1. }}$.

\section{Motivación de los estudiantes como herramienta discursiva y Derecho internacional privado. Ethos, pathos, logos}

30. La motivación de los estudiantes constituye una herramienta discursiva de capital importancia. Los más importantes estudios sobre enseñanza del Derecho así lo confirman ${ }^{52}$. Debe superarse, así, la llamada "pasividad del estudiante medio de nuestras facultades", cuya aspiración máxima suele ser la mera superación de la asignatura en su evaluación ${ }^{53}$. Aprobar la asignatura es para muchos estudiantes el nirvana, lo único. Para motivar al estudiante, pues, para que aprenda Derecho internacional privado y no sólo para que supere sus exámenes relativos a la asignatura, las tres grandes estrategias clásicas de origen griego son plenamente válidas también en el siglo XXI en relación con el Derecho internacional privado.

\section{Ethos: el Derecho internacional logra resultados justos}

31. En primer lugar, el ethos. Se puede y se debe motivar a los estudiantes si se muestra el alto valor del Derecho internacional privado para producir resultados justos ${ }^{54}$. Que una persona conserve su nombre y apellidos aunque traslade su residencia a otro país es justo (art. 1 del Convenio de Munich 5 septiembre 1980 [ley aplicable a los nombres y apellidos] y STJCE 14 octubre 2008, C-353/06, Grunkin-Paul $)^{55}$. Esa idea dinamiza todo el sistema de Derecho internacional privado. Le otorga un poder muy notable para adaptarse a la realidad, indican H.-P. MANSEL / K. THORN / R. WAGNER ${ }^{56}$. Además, tras esa idea, explica P. MANKowsKi, late un principio de confianza mutua en la Justicia extranjera que evoca una percepción universal de la Justicia ${ }^{57}$.

También es justo, como ha mostrado S. Huber, que un consumidor que adquiere por Internet ciertos pequeños electrodomésticos que luego resultan no funcionar, pueda demandar ante las autoridades del Estado donde tiene su domicilio y no tenga que demandar al vendedor ante los tribunales del

51 P. Kinsch, "Le rôle du politique en droit international privé. Cours général de droit international privé", Recueil des Cours de l'Académie de Droit international de La Haye, 2019, tome 402, pp. 9-384, esp. pp. 10-14.

52 Vid., inter alia, G. QuINTERo Olivares, La enseñanza del Derecho en la encrucijada (Derecho académico, docencia universitaria y mundo profesional, Cuadernos Civitas, Thompson Reuters, Madrid, 2010; E. LINDE PANIAGUA, El proceso de Bolonia: un sueño convertido en pesadilla, Cuadernos Civitas, Thomson Reuters, Madrid, 2010; J.R. CAPELLA, El aprendizaje del aprendizaje (una introducción al estudio del Derecho), Trotta, Madrid, 1995; F. GómEz DE LiAÑo, De los jueces, de los abogados y de los juicios, Civitas, Madrid, 2010; J.E. Bustos PuEche, "Reflexiones boloñesas con ocasión de la jubilación", en El Derecho internacional privado entre la tradición y la innovación (obra homenaje al profesor doctor José María Espinar Vicente), Iprolex, ISBN 9788494105593, Madrid, 2020, pp. 175-184; L. PeÑuELAs i ReIXACH, La docencia y el aprendizaje del Derecho en España, $3^{\mathrm{a}}$ ed., Marcial Pons, Barcelona-Madrid-Buenos Aires, 2009.

53 A. Gordillo, El método en Derecho, Civitas, Madrid, 1988 (reimp.1995), pp.117-135. Y. Romero Matute, “Cambiar el concepto de aprobar y buscar la necesidad de aprender", en M.A. CEBRIÁN SALVAT / I. LoRENTE MARTínez (directoras), Innovación docente y Derecho internacional privado, Ed. Comares, Granada, 2019, pp. 53-62.

54 Vid. en general F. Galgano, Il rovescio del Diritto, Milano, Giuffré, 1991; F. Galgano, Tutto il rovescio del diritto, Giuffrè, Milano, 2007.

55 Convenio relativo a la ley aplicable a los nombres y apellidos, hecho en Munich el 5 septiembre 1980 (BOE núm.303 de 19 diciembre 1989); STJCE 14 octubre 2008, C-353/06, Grunkin-Paul [Recopilación, 2008, p. I-07639] [ECLI:EU:C:2008:559].

56 H.-P. Mansel / K. Thorn / R. WAGner, "Europäisches Kollisionsrecht 2010: Verstärkte Zusammenarbeit als Motor der Vereinheitlichung?", IPRax, 2011-I, pp. 1-30.

57 P. Mankowski, "Nun sag, wie hast Du's mit dem Anerkennungsprinzip? - Im EU-Ausland ,unrechtmäßig“ erlangte Namen als Prüfstein", IPRax, 2020, n.4 vol. 40, pp. 323-329. 
Estado de la sede de la empresa vendedora (art. 17.1.c) RB I-bis) ${ }^{58}$. Ello es especialmente así, especialmente más adecuado, precisa de nuevo P. MANKOwSKI, en los casos de adquisiciones por Internet precedidas de publicidad realizada en dicho medio por el empresario vendedor ${ }^{59}$.

Sintoniza con una idea innata de Justicia también el forum damni y la regla lex damni: el foro del lugar del daño y al aplicación de la Ley del Estado en el que se ha producido el daño en los casos de responsabilidad no contractual. Es justo, así, que si un bien ha sido adquirido por Internet a un empresario con sede en el Estado A pero causa daños en el Estado B, la víctima pueda demandar a los responsables de dicho daño ante los tribunales del Estado B y con arreglo al Derecho de dicho Estado. Es la legítima expectativa del adquirente en virtud del principio de seguridad jurídica y de protección del consumidor, que son principios con rango constitucional en Derecho español y también principios fundamentales en Derecho europeo, explica E. CAstellanos Ruiz ${ }^{60}$.

En suma, la mejor motivación para que los estudiantes deseen aprender Derecho internacional privado radica en mostrar que éste puede hacer Justicia, que es un arma imbatible para alcanzar resultados justo en la sociedad líquida e híperveloz del siglo XXI.

\section{Pathos: el Derecho internacional privado mueve los corazones}

32. En segundo término, el pathos. Se trata de apelar a las emociones del que aprende Derecho internacional privado. El ser humano dispone de una parte racional y también de una parte emocional que es no racional. El Derecho internacional privado es atractivo porque (con-)mueve las almas de los seres humanos. Porque provoca emociones en las personas. La "emoción" es lo que mueve a la persona, pues en efecto la palabra "emoción" deriva del vocablo latino "emotio", y ésta su vez se toma del verbo "emovere", que significa "lo que mueve". Las emociones que experimental los seres humanos son aquellas experiencias que permiten que la persona abandone su estado habitual para conducirlas a un lugar nuevo. La emoción mueve y (con-)mueve a las personas.

33. En este escenario, el Derecho internacional privado aparece como un sistema de normas que hace posible que el amor supere las fronteras de los Estados, pues facilita por ejemplo, que un matrimonio celebrado en Moscú con arreglo a la forma legalmente prevista en Derecho ruso, sea considerado válido para el Derecho español (art. 49.1 CC) ${ }^{61}$.

Permite también, por ejemplo, que un niño que ha nacido tras una gestación por sustitución en un país que admite dicha práctica no se quede sin padres en otros países incluso aunque tal gestación por sustitución sea considerada ilegal en el Estado de destino del menor, como corrobora la jurisprudencia del TEDH y la jurisprudencia francesa más reciente ${ }^{62}$. Es decir, que la familia legalmente formada con arreglo a la Ley de un país sea considerada también una "familia" en los demás países pues no importa

${ }^{58}$ S. HuBER, "Das weite Verständnis des Verbrauchergerichtsstands im Europäischen Zuständigkeitssystem”, IPRax, 2020, n. 5 vol. 40, pp. 408-414.

59 P. ManKowski, “Autoritatives zum „Ausrichten“ unternehmerischer Tätigkeit unter Art. 15 Abs. 1 lit. c EuGVVO”, IPRax, 2012-II, pp. 144-156.

${ }^{60}$ E. Castellanos Ruiz, "El concepto de actividad profesional «dirigida» al Estado miembro del consumidor: stream-ofcommerce", Cuadernos de Derecho Transnacional CDT, 2012, pp. 70-92.

${ }^{61}$ Por analogía con el sistema español, vid. G.P. Romano, "La bilateralité éclipsée par l'autorité. Développements récents en matière d'état des personne", Revue critique de droit international privé, 2006, pp. 457-520.

62 STEDH 26 junio 2014, 65192/11, Mennesson vs. Francia] [ECLI:CE:ECHR:2014:0626JUD006519211]; STEDH 26 junio 2014, 65941/11, Labassee vs. Francia [ECLI:CE:ECHR:2014:0626JUD006594111]; STEDH 27 enero 2015, Paradiso et Campanelli vs. Italia [ECLI:CE:ECHR:2015:0127JUD002535812]; STEDH 21 julio 2016, Foulon y Bouvet vs. Francia_[ECLI:CE:ECHR:2016:0721JUD000906314]; STEDH Gran Sala 24 enero 2017, Paradiso Campanelli [ECLI:CE:ECHR:2017:0124JUD002535812]; Advisory Opinion (Grand Chamber of the ECHR) (Request no. P16-2018-001) of 10 April 2019 [http://hudoc.echr.coe.int/eng?i=003-6380464-8364383]; Decisión (Sección quinta) TEDH de 19 noviembre 2019, Cy E vs. Francia [ECLI:CE:ECHR:2019:1119DEC000146218]. Vid. también Sent. Cour cassation Francia n. 648 de 4 octubre 2019, Mennesson [ECLI:FR:CCASS:2019:AP00648]; Sent. Cour Cassation Francia n. 1113 de 18 diciembre 2019 [ECLI:FR:CCASS:2019:C101113]. 
tanto "cómo ha llegado el niño al mundo" que "cómo defender el interés de dicho niño una vez que está en este mundo", apunta S. SHAKARGY ${ }^{63}$. En relación con estos casos, el pathos muestra al jurista que una regulación jurisprudencial internacional, -como la generada por los casos fallados por el TEDH-, es más indicada que un enfoque legal estrictamente nacional, que se ha visto totalmente superado en la práctica, según observa C. Fenton-GLYNN ${ }^{64}$.

También el pathos estimula al estudiante del Derecho internacional privado cuando se le muestra la extraordinaria utilidad de esta disciplina jurídica. Los estudiantes deben ser conscientes de que, al aprender Derecho internacional privado, adquieren conocimientos, competencias, destrezas y habilidades que les resultarán operativos cuando se integren en la sociedad. Un saber útil motiva y el Derecho internacional privado es una disciplina jurídica con la que, a diferencia de otras ramas jurídicas, un buen jurista puede ganarse la vida.

\section{Logos: el Derecho internacional constituye un discurso intelectual y estéticamente bello}

34. En tercer lugar, el logos. El discurso del Derecho internacional privado es lógico, lineal, dispone de unas reglas que se verifican y ese respetan en todo su discurso, que aparece, así, sólido y ordenado. Se puede hablar, en este sentido, del "cosmos del Derecho internacional privado". En efecto, "kosmos" significa, en lengua griega, "orden" y curiosamente, al mismo tiempo, significa también "bello". De ahí, por ejemplo, la palabra "cosmético", que es aquello que aumenta la belleza. Pues bien, los razonamientos y soluciones del Derecho internacional privado son lógicos, son ordenados, son coherentes y por ello, son también bellos al mismo tiempo, elegantes, apunta, para el Derecho internacional privado europeo, F. WILKE ${ }^{65}$.

35. La belleza intelectual y estética del Derecho internacional privado mueve también a los estudiantes, que aprecian la elegancia discursiva de un razonamiento ordenado, coherente, lineal, razonable y equilibrado propio del Derecho internacional privado. Un ejemplo puede resultar útil a este respecto. En un caso en el que se trata de aclarar cuál es la Ley aplicable a la sucesión de un nacional español que ha otorgado testamento ológrafo en Londres y cuyo patrimonio está formado por bienes situados en Francia y España, la primera cuestión a resolver es la (i) calificación de un testamento ológrafo como cuestión sucesoria. La segunda cuestión es (ii) la aplicación del Reglamento sucesorio europeo para fijar la Ley aplicable a la sucesión del nacional español. La tercera cuestión que aparece de modo lineal en el horizonte de sucesos es la (iii) aplicación de la Ley española al testamento ológrafo que contiene una professio juris en favor del Derecho español por parte del causante español cuya residencia habitual se encontraba en Londres. Finalmente, la cuarta cuestión radica en el (iv) reparto de las legítimas entre los herederos forzosos según el Derecho español aplicación y no aplicación del Derecho inglés. El estudiante que aprecia la inmarcesible belleza de la argumentación del Derecho internacional privado se siente inmediatamente cautivado por esta disciplina jurídica. Debe subrayarse, en todo caso, que todo el Derecho constituye un saber aporético, problemático, en el que no es posible hallar resultados aritméticos, algebraico, fijos e inmutables. El Derecho internacional privado invita a una argumentación tópica en la que caben razonamientos y explicaciones distintas, diferentes e incluso opuestas y todas ellas, al mismo tiempo, posibles en el marco de una correcta dogmática jurídica ${ }^{66}$.

\footnotetext{
${ }_{63}$ S. ShaKARGY, "Choice of law for surrogacy agreements: in the in-between of status and contract", Journal of Private international law, 2020, n.1, vol. 16, pp. 138-162.

${ }^{64}$ C. Fenton-Glynn, "International surrogacy before the European Court of Human Rights", Journal of Private International Law, vol. 13, 2017, issue 3, pp. 546-567.

${ }^{65}$ F. WILKE, A conceptual analysis of European private international law, the general issues in the EU and its Member States, Ed. Intersentia, 2019, pp. 12-14.

${ }^{66}$ A.I. Oliveros, "Vértigos argumentales", en L. Vega Reñón / P. Olmos Gómez (eds.), Compendio de lógica, argumentación

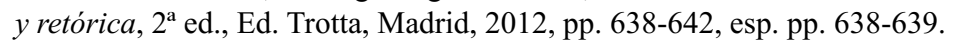




\section{Contexto democrático de la enseñanza del Derecho internacional privado}

36. Cuando se hace referencia a un contexto democrático de la enseñanza del Derecho internacional privado no se pretende aludir a una realidad vacía o a un juego de palabras, mero toreo de salón, brindis al sol y pedaleo de gimnasio. Se hace referencia, por el contrario, a un ambiente axiológico que funciona como presupuesto básico de una correcta enseñanza del Derecho internacional privado. Ello es necesario para alcanzar un resultado satisfactorio en la labor docente del Derecho internacional privado. Dicho contexto funciona en dos niveles.

\section{EI Derecho internacional privado es un saber argumentativo}

37. En un primer nivel, los objetivos docentes a conseguir deben valorarse desde la argumentación y no desde la imposición de teorías fijas e inmutables. La formación de los estudiantes, entendida en un sentido general, -cultural y jurídica-, y particular, -en relación al Derecho internacional privado-, debe realizarse mediante una dosis ingente de argumentación y contraste de soluciones, teorías, posiciones y consecuencias (= es la "enseñanza reflexiva" del Derecho internacional privado). Afirmar, sin más, que la calificación para determinar la Ley aplicable debe realizarse siempre con arreglo al Derecho español, como indica el art. 12.1 CC, resulta apodíctico, algebraico y transmite una idea de opresión intelectual. Es preciso, para una enseñanza argumentada del Derecho internacional privado, que el docente de la materia explique los motivos que llevaron al legislador español a seguir esa solución, y cuáles eran y son las alternativas posibles. De ese modo se alcanza una dinámica estructural interiorizada, ya que se motiva en los receptores la aprehensión de los argumentos más razonables y justificados, aquéllos que pueden convencer con mayor dosis de moderación, sensatez y prudencia.

\section{Modo constitucional y modo europeo de pensar el Derecho internacional privado}

38. En un segundo nivel, el contexto referido debe procurar que las soluciones a las que se llega mediante la aplicación de las normas de Derecho internacional privado se examinen y se ponderen mediante el grado de consecución y protección de los valores constitucionales del Derecho español y de los valores jurídicos europeos del Derecho de la Unión Europea y recogidos, básicamente, en los derechos fundamentales de este ordenamiento. Es importante trasmitir a los estudiantes la idea de que los valores, las normas y los standards culturales son tres realidades distintas también en Derecho internacional privado y que son los valores los que ocupan, en un discurso comprometido, un escalón superior en el zigurat de la argumentación jurídica, escribe M.V. CARAUSAN ${ }^{67}$.

39. En el sentido apuntado, los estudiantes deben asumir que las soluciones directamente derivadas del cuadro de valores constitucionales y del Derecho europeo son las que cuentan con un respaldo jurídico de mayor intensidad al trata de convencer en un debate jurídico de Derecho internacional privado. Cuestiones tan complejas como el conflicto de civilizaciones, las corrientes migratorias, el status de extranjería del no nacional, la autonomía de la voluntad conflictual, la protección de los consumidores y trabajadores, el medio ambiente, e incluso la precisión del elenco de fuentes del Derecho internacional privado son aspectos objeto de perenne debate en el cual las soluciones con respaldo constitucional son las que presentan un mayor peso argumentativo. Es función del docente de Derecho internacional privado fomentar el "modo constitucional de pensar" y también el "modo europeo de pensar" y argumentar en los estudiantes. En esta línea, por ejemplo, mostrar por qué el art. 6 RR-I opta, como punto de conexión básico y general, por la "residencia habitual del consumidor", exige realizar una lectura constitucional y europea de dicha norma de conflicto, en sintonía clara con el art. 51 Constitución española y con el art.

${ }^{67}$ M.V. CARAUSAN, "Is European Union at the Heart of Citizens' Identity?", Juridica, 2011, p. 59, available at SSRN: https://ssrn.com/abstract=1987158. 
169 TFUE $^{68}$. Si ello se consigue, se logrará una adecuada formación del estudiante en este sector y, al mismo tiempo, se le habrá enseñado un modo constitucional y europeo de argumentación jurídica que le servirá. Ello servirá, igualmente, para destacar y promover la función del Derecho internacional privado como instrumento de los valores constitucionales y europeos, lo que no siempre el legislador tiene tan claro, subraya J. MeEusen ${ }^{69}$. Finalmente, también pude destacarse que, visto que la democracia es una valor social del más alto nivel tanto desde el punto de vista constitucional español como desde el punto de vista del Derecho europeo, resulta extremadamente interesante cuestionarse acerca de la presencia de la democracia en as soluciones positivas del Derecho internacional vigente, como ha sugerido sagazmente J. WOUTERs ${ }^{70}$.

\section{Reflexiones}

40. El Derecho internacional privado constituye una disciplina jurídica fascinante. Sin embargo, su enseñanza exige un proceso de clarificación intelectual por parte del docente que permita la transmisión del potencial de cambio social, personal e intelectual que atesora el Derecho internacional privado. El secreto, como casi todo en la vida, descansa en la motivación necesaria que debe poseer el estudiante de Derecho internacional privado. El docente de Derecho internacional privado puede potenciar esa motivación mediante una transmisión del Derecho internacional privado como sector del Derecho que permite alcanzar resultados justos y emocionantes a través de un discurso intelectualmente sugestivo y estéticamente atractivo. El buen docente del Derecho internacional privado es, así, el que, en el contexto de la erística jurídica, consigue llegar tanto en la parte racional como en a la parte emocional del estudiante. Los estudiantes motivados de hoy son los profesionales diligentes del mañana.

\footnotetext{
68 Artículo 51.

1. Los poderes públicos garantizarán la defensa de los consumidores y usuarios, protegiendo, mediante procedimientos eficaces, la seguridad, la salud y los legítimos intereses económicos de los mismos.

2. Los poderes públicos promoverán la información y la educación de los consumidores y usuarios, fomentarán sus organizaciones y oirán a éstas en las cuestiones que puedan afectar a aquéllos, en los términos que la ley establezca.

3. En el marco de lo dispuesto por los apartados anteriores, la ley regulará el comercio interior y el régimen de autorización de productos comerciales.

Artículo 169 (antiguo artículo 153 TCE):

1. Para promover los intereses de los consumidores y garantizarles un alto nivel de protección, la Unión contribuirá a proteger la salud, la seguridad y los intereses económicos de los consumidores, así como a promover su derecho a la información, a la educación y a organizarse para salvaguardar sus intereses.

2. La Unión contribuirá a que se alcancen los objetivos a que se refiere el apartado 1 mediante:

a) medidas que adopte en virtud del artículo 114 en el marco de la realización del mercado interior;

b) medidas que apoyen, complementen y supervisen la política llevada a cabo por los Estados miembros.

3. El Parlamento Europeo y el Consejo, con arreglo al procedimiento legislativo ordinario y previa consulta al Comité Económico y Social, adoptarán las medidas mencionadas en la letra b) del apartado 2.

4. Las medidas que se adopten en virtud del apartado 3 no obstarán para que cada uno de los Estados miembros mantenga y adopte medidas de mayor protección. Dichas medidas deberán ser compatibles con los Tratados. Se notificarán a la Comisión.

69 J. Meeusen, "Comparing Interstate and European Conflict of Laws from a Constitutional Perspective: Can the United States Inspire the European Union?", American journal of comparative law, 2019-3, pp. 637-676.

70 J. Wouters, "Le statut juridique des standards publics et privés dans les relations économiques internationales", Recueil des cours de l'Académie de droit international de La Haye, 2020, t. 407, pp. 9-122, esp. pp. 111-119: "Comment assurer la démocratie dans des processus largement privés?".
} 